\title{
As margens da política como parte constituinte e indissociável do Estado em ação
}

\section{NATIVIDADE, Marcelo}

Margens da política: Estado, direitos sexuais e religióes

Rio de Janeiro: Garamond, 2016. 296p.

| ${ }^{1}$ Guilherme de Souza Rangel da Silva I

1 Universidade Federal do Rio de Janeiro. Rio de Janeiro-RJ, Brasil (gh.farma@gmail.com). ORCID: 0000-0002-6239-4629

Recebida em: 28/09/2018

Aprovada em: 13/12/2018

Revisada em: 14/07/2019

DOI: http://dx.doi.org/10.1590/S0103-73312019290320

Pensar as forças que o Estado mobiliza como um grande e pervasivo fluxo pluvial que contorna toda sociedade e atravessa seus distintos territórios, porém com margens sujeitas a marés altas e baixas, erosóes e reconstruçóes. Trata-se de uma expressiva metáfora utilizada como eixo estruturante do livro Margens da política: Estado, direitos sexuais e religióes, publicado em 2016 pelo antropólogo, jornalista e professor da Universidade Federal do Ceará, Marcelo Natividade.

Durante todo o percurso, Natividade náo nos deixa esquecer que no leito desse rio, cujas águas são as políticas públicas assinadas pelo Estado em ação, estão os centros institucionais de poder em que nadam grupos sociais privilegiados que determinam e controlam as normas hegemônicas; e que nas margens do rio, instáveis e provisórias, estão outros grupos sociais que ficam à deriva, com visibilidade, legitimidade e inteligibilidade em situação precária. Quando o autor aponta as dimensôes "Estado", "direitos sexuais" e "religiáo", o subtítulo do livro já indica por quais águas, nada tranquilas, vamos viajar.

A obra é resultado de quatro anos de pesquisas, relativos ao seu estágio pósdoutoral desenvolvido no Programa de Pós-Graduação em Antropologia Social do Museu Nacional/UFRJ, e ao projeto de pesquisa "O Estado em ação: etnografia de políticas públicas de combate à discriminação sexual e desigualdade de gênero", 
desenvolvido na Universidade Federal do Ceará e posteriormente no Departamento de Antropologia da Universidade de São Paulo.

$\mathrm{O}$ autor, até então com vasto conhecimento acadêmico na estreita fronteira do campo da experiência dos sujeitos, pastorais sexuais e mecanismos de produção de subjetividade, chega a admitir no epílogo de Margens da política que o conjunto da obra é resultado do trabalho em um campo não tão íntimo: o do Estado e suas políticas públicas. Porém, a rica construção metodológica, aliada à vasta pesquisa documental e à densa análise etnográfica, não deixa transparecer tal ausência de intimidade.

No preâmbulo, somos informados de que os protagonistas da obra são "pessoas e identidades que reivindicam reconhecimento público e políticas de proteção do Estado através de processos sociais múltiplos, em distintos contextos culturais" (NATIVIDADE, 2016, p. 21). Abordam-se resistências e lutas para se conquistar direitos e ter acesso aos já legalmente estabelecidos. Estão presentes conflitos, ambiguidades, negociações e afirmaçóes identitárias de grupos cujo desejo sexual desafia as normas hegemônicas e, justamente por isso, estão às margens da política. Mas o que são as margens da política? Quais suas características intrínsecas? Como elas funcionam como mecanismo de organização política?

Para fundamentar este conceito central do livro, Natividade recorre ao antropólogo francês Van Gennep (2011) e suas preocupaçôes com o tema da liminaridade, cuja abordagem deslocava o foco dos centros convencionais de poder para as margens da vida social, com o olhar voltado para paradoxos, ambiguidades e zonas intersticiais em perspectivas minoritárias. A antropologia das marginalidades começa a florescer na década de 1960 e passa a figurar em trabalhos de nomes como Mary Douglas (1979) e Victor Turner (2005), até chegar nos anos 2000 com notáveis pesquisas e insights da antropóloga indiana Veena Das (2007) - talvez a maior inspiração teórica de Natividade no decorrer de todo o livro.

Não há uma fronteira nítida entre os domínios sociais contrários ou favoráveis aos direitos e causas LGBT, que avançam em zonas divisórias de caráter dúbio, condicional e circunstancial onde nada é garantido; toda conquista pode ser desfeita e tentativas precisam sempre recomeçar (BIRMAN, 1995). As políticas conservadoras embasadas por princípios cristãos são hegemônicas, mas não escapam de um campo sensível de disputas com as pautas LGBT. Existe uma intensa necessidade, de ambos os lados, de legitimação de suas urgências pelo Estado, uma vez que, nos embates de poder, a potência dos dispositivos legais é ampla. 
Contudo, no decorrer do livro, a etnografia de Natividade consegue evidenciar que a força da lei é amplamente amparada por princípios religiosos, com força substancial para jogar as pautas LGBT nas margens da política, cabendo a elas resistir e nadar contra a corrente, impulsionadas por sua forte militância. Neste ponto, começam a tomar forma as reflexôes de Venna Das (2007), trazidas por Natividade como em "é por meio da observação que se desloca entre o oficial (a intenção da política) e os sujeitos e seus anseios, que se apreendem sentimentos de consideração ou de desconsideração pelo Estado" (DAS, 2007; NATIVIDADE; NAGAMINE, 2016). Ou seja, só se atentando às margens é que conseguiremos observar avanços e recuos; disputas e alinhamentos. O Estado "é interpretado como ameaça e também como garantia de direitos” (NATIVIDADE, 2016, p. 25). Ele constitui margens de visibilidade e legitimidade, produzindo zonas de exclusão e de inclusão. Quando se observam contextos locais, ao mesmo tempo em que se apreende como o Estado gerencia as populaçóes na margem, evidencia-se o modo como essas mesmas populaçôes conseguem se movimentar nas lacunas entre leis e sua implementação.

Ainda apoiando-se em Veena Das (2007), Natividade finaliza o último capítulo do livro concluindo e reforçando que o apreço e a acolhida das agendas dos movimentos LGBT pelo Estado (tomado aqui como uma malha complexa, atravessada por interesses, conflitos e negociaçóes) dependem, sobretudo, das configurações políticas que estão postas em dado momento do contexto local.

Serão esses contextos locais, apresentados capítulo por capítulo, que irão nos revelar que a margem não deve ser percebida "como um lugar de externalidade ou de exclusão referente aos poderes do Estado: ela é parte integrante e constitutiva do próprio Estado.” (NATIVIDADE, 2016, p. 267).

No primeiro capítulo, "Entre reconhecimento e demonização", o contexto eleito para análise é a Baixada Fluminense, no estado do Rio de Janeiro. Natividade evidencia a pluralidade e constante diversificação da região, especialmente no que se refere a moralidades e percepçóes da diferença. Um ponto que chama a atenção é o célere crescimento da população evangélica nessas áreas periféricas, ao mesmo tempo em que o Brasil é um país de maioria e ethos católico. Logo, o olhar antropológico sobre os marcadores sociais e as vulnerabilidades LGBT desse contexto local poderiam trazer importantes evidências sobre como o Estado tem administrado estes grupos que estão nas margens. Três casos se destacam como fonte de reflexão. 
O primeiro, que aborda a implantação de uma "igreja inclusiva" no município de Nova Iguaçu, favorecendo a compreensão do cristianismo em movimento, em que a associação religião-conservadorismo perde certa força.

O segundo caso acompanha a implantação e o encerramento do Programa de Saúde LGBT, também em Nova Iguaçu. Pareceres solicitando a continuidade do programa foram negados, com o argumento de que "não eram açôes prioritárias" para o município. Apesar de não invocar valores religiosos na justificativa, o pertencimento religioso entrou em cena para desarticular diferentes açôes de proteção à cidadania dessas pessoas.

O terceiro caso ampara-se na etnografia das paradas pela diversidade sexual nos munícipios da Baixada Fluminense, especialmente a de Duque de Caxias. Nesse contexto, manifestaçóes da diversidade sexual não eram vistas como uma necessidade local, configurando dinâmicas de negociaçáo para que as minorias políticas pudessem ocupar o espaço público. O extremo ocorreu em Duque de Caxias quando sua VI Parada do Orgulho LGBT foi cancelada por pressão de grupos religiosos. Uma crescente controvérsia tomou o espaço público. Pastores evangélicos e Igreja Católica enviaram cartas à prefeitura reprovando o evento, que o prefeito considerava ser contrário aos valores da família. O pânico moral em torno do chamado "atentado ao pudor" foi acionado quando se cogitou realizar a parada na principal avenida da cidade, uma área residencial.

O segundo capítulo, "Para além das oposiçōes", focaliza as controvérsias envolvidas no debate político das eleições de 2010, incluindo a união civil homoafetiva e a adoção homoparental. O pleito para o governo do Rio de Janeiro foi particularmente interessante porque explicitou a patente relação entre política, religião e diversidade sexual no momento em que direitos LGBT são acionados como elemento desqualificador de adversários políticos. Durante ato de campanha na Baixada Fluminense, o candidato Anthony Garotinho trouxe à tona o tema do "casamento gay" para rechaçar seus adversários Fernando Gabeira e Sérgio Cabral, supostamente apoiadores da pauta. A controvérsia foi disparada no espaço público com auge no segundo turno das eleiçôes presidenciais. O então candidato José Serra se comprometeu com setores religiosos a vetar a "lei anti-homofobia", e foi criticado por religiosos apoiadores da candidata Dilma Rousseff, dentre os quais Marcelo Crivella, que chegou a afirmar que "nenhum candidato que pregue a homofobia pode ser eleito". No entanto, ele próprio fez parte do coro que pressionava Dilma a se posicionar 
contra qualquer proposta que fosse contra os valores religiosos, incluindo o casamento homossexual. Chegou-se ao ponto de a presidente Dilma assinar documento junto a instituiçóes religiosas comprometendo-se com o respeito aos dogmas da Igreja.

A esfera de influência de setores religiosos no cenário eleitoral brasileiro é tão marcada, que passa a ser objeto de disputas entre os principais candidatos à presidência, que se submetem a todo e qualquer tipo de exigência em troca de apoio político e eleitoral, sendo os direitos reprodutivos e sexuais objeto preterido de negociação. $O$ tema das eleiçôes salienta a constante negociação e redefinição contextual dos posicionamentos quando o que está em pauta são os direitos políticos dos que estão às margens. Em variados momentos do livro, Natividade se refere a esta dinâmica das interaçôes como o "jogo da política” e conclui o capítulo com a defesa de uma concepção desessencializada da política, concebendo posiçóes que devam ir além das polaridades do "ser contra" ou "ser a favor", mas que evidenciem os contornos que são próprios do jogo da política.

O terceiro capítulo, "Estado em ação", continua com a abordagem do jogo da política, que agora é descortinada sob o ponto de vista de duas etnografias realizadas por Natividade: uma na região metropolitana de Fortaleza, Ceará, e outra na do Rio de Janeiro. Ambas foram eleitas com a justificativa de serem pioneiras em açóes de defesa a populaçôes não heterossexuais no âmbito legislativo, com práticas orientadas pelo Programa Nacional Brasil Sem Homofobia, que em seguida inspiraram açóes em municípios vizinhos.

O Programa Rio Sem Homofobia foi lançado em 2009, porém tem raízes na promessa eleitoral do entáo candidato Sérgio Cabral, em 2006, ao assinar a "Carta compromisso por um Rio sem Homofobia”. Já "Fortaleza Bela”, marketing da prefeitura de Luizianne Lins (PT) entre 2005 e 2012, tinha como um dos objetivos a integração da população LGBT ao espaço público, incluindo açôes de cultura, lazer e esporte, além de várias iniciativas no campo legislativo. Em 2013, após a eleição de Roberto Claudio (PSB) como novo prefeito da capital do Ceará, toda mobilização estatal pró-LGBT perdeu força e espaço, pois se configuraram outras prioridades do ponto de vista da atual gestão. Até mesmo políticas medulares, como as de HIV/ Aids, perdem status, por ainda estarem fortemente associadas aos homossexuais, existindo até mesmo casos em que religiosos questionam o uso do dinheiro público para tal finalidade. 
Focalizar grupos específicos, nesse contexto, é visto como tratamento desigual. Natividade segue a linha de reflexão de Lila Abu-Lughod (2013), quando afirma que "direitos possuem uma vida social complexa, podendo envolver articulações entre níveis local e global” (NATIVIDADE, 2016, p. 112). Deste modo, as etnografias desse capítulo acabam por auxiliar na compreensão da permeabilidade do "Estado em ação" aos emaranhados locais quando o objeto de desígnio são as margens, as zonas de instabilidade. Nesses espaços de interstícios, até mesmo a perspectiva vital e urgente dos direitos humanos não consegue ser acessada, repelida pela hegemonia do contexto religioso local.

No quarto capítulo, escrito em co-autoria com Aline Soares Alves, "Sobre LGBTs, corporaçôes e políticas de segurança pública”, são etnografados alguns casos de homofobia institucional e homofobia cordial, e como elas entram em confronto com as redefinições e negociaçóes do Estado, ao ceder políticas públicas de reconhecimento das margens. O esquema de segurança realizado para a $14^{a}$ Parada pela Diversidade Sexual da cidade de Fortaleza (CE) evidenciou uma disputa entre visões de mundo sobre quem deve ou não deve ter direitos na sociedade brasileira. Enquanto o grupo das sexualidades dissidentes enfatizava a normalidade de todas as orientaçóes sexuais e legitimava a luta por equidade de direitos, do outro lado a massa dos agentes estatais de segurança pública negava inteligibilidade às identidades dissidentes, condenando suas condutas públicas e deslegitimando posturas de aceitação. Deste modo, realçavam-se os imperativos morais que consideravam as práticas homossexuais desrespeitosas aos valores da família e da religião.

A visibilidade dessas identidades e manifestaçóes pró-LGBT no espaço público era motivo de acentuado desconforto. A norma deveria ser pela rejeição que, agora, é retratada na segunda parte do capítulo sob outra perspectiva: a partir de dentro das corporaçôes de segurança, em entrevistas com um gay e uma lésbica, ambos da Guarda Municipal e "assumidos". Além dos relatos de violação aos direitos humanos sofridos por outros guardas que não se encaixavam nos padróes heteronormativos dentro da corporação, os contornos exigidos para um aprendizado social específico do que é ser gay ficam sinalizados em suas narrativas. São processos de construção de si utilizados para sustentar a homossexualidade em um dado contexto. De acordo com os depoimentos de ambos informantes, para assumir publicamente a homossexualidade dentro da Guarda Municipal de Fortaleza, é necessário "ter postura". A postura envolve engajamento na discrição e a expressão de um ethos viril, que devem resultar 
no apagamento de qualquer traço de feminilidade, pois a feminilidade masculina é sinônimo de vergonha para a corporação; já a feminilidade feminina é sinônimo de fragilidade, por isso, segundo a informante, lésbicas masculinizadas são vistas com mais respeito do que qualquer outra mulher dentro da instituição.

Nesse momento, a investigação foi atravessada pela questão de gênero, reforçando a demarcação de margens entre guardas homossexuais e guardas heterossexuais; entre feminilidades e masculinidades. Para embasar a questão sobre como normas e regras das corporações militares impactam nos processos de construção de si, Natividade recorre aos conceitos de face (GOFFMAN, 1980) e fachada (GOFFMAN, 2007). As fachadas erguidas pelo agente público têm o intuito de apagar as marcas da homossexualidade, rótulos estigmatizantes e quaisquer associaçóes com o universo feminino, encenando cotidianamente uma imagem de si coerente com os modelos conservados pela instituição; uma face que prioriza a identidade de guarda e coloca em segundo plano a identidade homossexual.

O capítulo seguinte, "Entre hospitalidade e hostilidade", escrito em co-autoria com Renata Reverendo Vidal Nagamine, traz densa descrição e análise etnográfica dos debates envolvendo políticas sexuais no cenário global, incluindo a Comissão de Direitos Humanos e Minorias (CDHM) do Congresso brasileiro. Foram identificados movimentos em múltiplas direçôes, com condutas que operam através da hostilidade ou da hospitalidade, e que emergem de formas distintas e contextuais quando o que se está em jogo é a situação de pessoas LGBT. A controvérsia em torno da lei anti-homossexualidade ugandense e a aprovação do casamento igualitário irlandês são colocados pelos autores em lados opostos para evidenciar as múltiplas formas de ressignificaçóes e articulaçóes possíveis da atuação religiosa em torno das políticas das margens.

Com uma população em que $83,9 \%$ se denominam cristãos, Uganda se destacou através de uma controvérsia que tomou proporçóes globais, quando decidiu criminalizar a homossexualidade e qualquer tipo de "promoção" a ela, utilizando como justificativa os princípios da ordem natural e moral do discurso religioso. No entanto, o que chamou mais a atenção foi que, além da dimensão religiosa, acessou-se a justificativa científica, mais precisamente o construtivismo das ciências sociais. $\mathrm{Na}$ visão do governo ugandense, a homossexualidade seria fruto de uma construção social, orientada pelo Ocidente, através de ONGs com sede em países desenvolvidos e que se estabeleciam na África para promover o ativismo LGBT; 
quando na verdade se tratam de ONGs que agem na contenção do avanço do HIV-Aids naquele continente. Na perspectiva ugandense, se a homossexualidade é aprendida, ela também pode ser "curada" com a prática continuada dos papéis de gênero tradicionais. Enquanto a cura não acontecer, qualquer pessoa LGBT será considerada um inimigo interno, braço do imperialismo ocidental que ameaça a soberania nacional. A esses estranhos, toda hostilidade deve ser direcionada e nenhuma hospitalidade oferecida.

O caso ugandense trazido é cabal para esclarecer como determinados contextos podem levar à condição de estrangeiros, dentro de seu próprio país, grupos que se encontram nas margens da plena cidadania. Por outro lado, na Irlanda, um país de ampla maioria cristã e com forte presença da Igreja Católica, essa corrente de estranhamentos, medos e hostilidades não foi acionada. Valores cristãos foram reposicionados de forma distinta de como aconteceu em Uganda, e preceitos como o amor incondicional e a condenação da desigualdade foram mobilizados pela populaçáo para aprovar o casamento civil igualitário.

Distante dessa realidade e mais próximo de Uganda, está o cenário brasileiro. Natividade e Nagamine trazem uma breve discussão sobre a controvérsia da eleição do Pastor Marcos Feliciano para a presidência da Comissão de Direitos Humanos e Minorias (CDHM) da Câmara Federal, e da discussão inicial em torno da "cura gay" dentro dessa comissão. Os autores chamam a atenção para uma estratégia poderosa que vem ganhando cada vez mais prestígio no espaço público, especialmente no Congresso Nacional: o secularismo estratégico (VAGGIONE, 2005; 2011), em associação com a homofobia religiosa. Enquanto o secularismo estratégico lança mão do Direito e da ciência de formas ambivalentes para legitimar seu discurso, a homofobia religiosa se vale da máxima "negar o pecado mas amar o pecador", não demonstrando abertamente seu caráter excludente.

No último capítulo, em co-autoria com Leandro de Oliveira, "O que há de tão satânico na xereca da vizinha”, duas controvérsias públicas são utilizadas para extrair conclusôes e consideraçôes finais sobre toda a reflexão que o livro proporciona. A proposta do "translendário" promovida em Fortaleza, que remontava imagens da pintura clássica em um calendário, cujas personagens eram travestis e transexuais, tinha por objetivo dissociar deste grupo os estereótipos da prostituição e criminalidade, por meio de expressóes artísticas, deslocando-as da margem para a humanidade comum. O calendário, que antes da controvérsia representava uma 
ação benéfica contra o preconceito, devido à pressão de setores religiosos, passou a representar agora objeto de desestabilização. Essa controvérsia é reveladora porque mais uma vez traz à luz as instabilidades da margem. Até mesmo agentes do Estado que sempre foram comprometidos com a promoção de práticas de inclusão e respeito à diversidade, diante de novos acontecimentos, passam a adotar posiçôes mais refratárias quando a força religiosa aparece como agente de contenção.

A segunda controvérsia refere-se à performance "Xereca Satanik", que ocorreu na Universidade Federal Fluminense (UFF), em que se realizou a costura de uma genitália feminina para representar criticamente a violência sexual contra mulheres e a desapropriaçáo do corpo feminino expresso no estupro. Não demorou para que boatos como um "culto satanista" com "orgia e sexo em público" realizado por "drogados e alcoolizados" viessem à tona e o debate sobre o mau e bom uso do dinheiro público também surgisse para integrar a controvérsia. Mas além do dinheiro público, agora também se indagava sobre o bom e mau uso do corpo, objeto de relativa sacralização. O corpo vira assunto do Estado, materializando relaçóes de poder que comprimem ainda mais os que estão na margem.

As noçôes de pânicos sexuais elaboradas por Janice Irvine (2007) nos auxiliam a compreender o cerne da obra em estudo. Para vencer as disputas que travam contra aqueles que reivindicam o reconhecimento de suas sexualidades dissidentes, setores conservadores e religiosos manipulam as emoçôes coletivas, através de uma estrutura discursiva sofisticada e roteirizada que organiza crenças e moralidades; apropria-se de uma linguagem sexual evocativa do medo de transgressôes e perversóes sexuais; manipula imagens sensoriais que levam ao nojo; demoniza o "inimigo" a ser combatido (IRVINE, 2007). Essas estratégias fazem parte do roteiro que desperta pânicos sexuais, desencadeando emoçóes locais ferozes e reaçôes públicas voláteis que conseguem pressionar o Estado a dar uma resposta apressada às controvérsias, resultando geralmente em leis e políticas públicas que restringem direitos sexuais (IRVINE, 2007). Este é o modelo que se desenha em diversas situaçôes narradas por Natividade em seu livro. Surtos coletivos de ódio, medo e repugnância vão e voltam quando desencadeados pela percepção de que grupos LGBT estão fazendo grandes progressos. Tais ataques são originados pela apreensão de que há possibilidade real de avanços das sexualidades dissidentes, dando forma aos backlashes (FALUDI, 1991).

Chegamos à conclusão do livro com a clareza, proporcionada de forma magistral e persistente por Natividade e colaboradores, de que a política pública 
é instável e provisória nas margens. Nelas, categorias como liberdade, cidadania e direitos estão em constante disputa entre atores religiosos e minorias sexuais, sendo esta dinâmica e seu resultado condicionados, inevitavelmente, ao contexto local. No entanto, em todos esses contextos, o que se anseia, de ambos os lados, é a regulação do Estado: grupos LGBT assinalam expectativas de regulação na proteção de direitos, enquanto religiosos esperam a regulação estatal das condutas que desafiam a moralidade religiosa. Nesse jogo de forças em que o Estado é convocado a promover a liberdade e a igualdade, ao mesmo tempo em que é instado a regular corpos e promover a família e a religião, as hesitaçôes frente a essas demandas são percebidas, por ambos os grupos, como alianças obscuras e ilegítimas que devem ser confrontadas. A ausência de consensos, com diferentes leituras da lei, faz o autor questionar se realmente existe uma "unidade" da nação, com um Estado realmente laico e pluralista, ao se perguntar: "Quanta diversidade é possível acomodar dentro dela?” (NATIVIDADE, 2016, p. 264). Novamente, as análises de Venna Das (2007) sobre o paradoxo da assinatura do Estado alimentam as dúvidas de Natividade, mas também inspiram suas respostas:

[...] por ser um texto, a lei frequentemente é opaca; seu sentido não emana de supostos conteúdos intrínsecos ao texto, mas deriva do modo como este é apropriado nos contextos locais em que é acionado. A legibilidade da lei é um atributo em constante tensão com a iterabilidade da lei. (NATIVIDADE, 2016, p. 261).

Ou seja, nem mesmo os agentes do poder estatal conseguem realizar interpretaçóes em consonância sobre o entendimento da lei e suas aplicaçôes em cada caso. Esse conjunto de polifonia e dissensos é resultado do poder simultâneo da onipresença e ilegibilidade do Estado. O que Natividade vem propor e reforçar com Margens da política é, primeiramente, descongelar a imagem da religião como essencialmente conservadora e avessa à modernidade (LATOUR, 2004) e, principalmente, pensar o funcionamento da lei e do Estado em contexto, sempre exposto a uma legiáo de vozes em tensão, que oscilam entre avanços e recuos, divergências e consensos provisórios, indicando a complexa vida social dos direitos a que está submetida a diversidade dissidente, à deriva nas margens do Estado.

\section{Referências}

ABU-LUGHOD, L. Do Muslim women need saving? Cambridge: Harvard Univesity Press, 2013. BIRMAN, P. Fazer estilo criando gênero. Rio de Janeiro: Relume Dumará/EdUERJ, 1995. 
DAS, V. Life and words: Violence and the descent into the ordinary. Berkeley-Los Angeles: University of California Press, 2007.

DOUGLAS, M. Pureza e perigo. São Paulo: Perspectiva, 1976.

FALUDI, S. Backlash. The undeclared war against women. New York: Crown Publishers, 1991.

GOFFMAN, E. 2007. A representação do eu na vida cotidiana. Petrópolis: Vozes, 2007. . A elaboração da face. In: FIGUEIRA, S. Psicanálise e ciências sociais. Rio de Janeiro: Francisco Alves, 1980. p. 76-114.

IRVINE, J. Transient feelings: sex panics and the politics of emotions. A Journal of Lesbian and Gay Studies (GLQ). Philadelphia, v.14, p. 01-40, 2007.

LATOUR, B. Não descongelarás a imagem ou como não desentender o debate ciência-religião. Mana. Rio de Janeiro, v. 10, n. 2, p. 349-376, 2004.

NATIVIDADE, M.; NAGAMINE, R. Entre hospitalidade e hostilidade. In: NATIVIDADE, M. Margens da política: Estado, direitos sexuais e religióes. Rio de Janeiro: Garamond, 2016. p. 187-241.

TURNER, V. Floresta de símbolos. Aspectos do ritual Ndembu. Niterói: EdUFF, 2005.

VAGGIONE, J. M. Reactive policitization and religious dissidence: The political mutations of the religious. Social Theory and Practice, v. 31, n. 2, p. 233-255, 2005.

. Sexualidad, religión y política en América Latina. In: CORREAA, S.; PARKER, R. (Orgs.). Sexualidade e politica na América Latina: histórias, interseçôes e paradoxos. Rio de Janeiro, ABIA, 2011. p. 286-336.

VAN GENNEP, A. Os ritos de passagem. Petrópolis: Vozes, 2011. 